\title{
Selective Laser Melting of 30CrMnSiA Steel: Laser Energy Density Dependence of Microstructural and Mechanical Properties
}

\author{
Lin-Zhi Wang ${ }^{1} \cdot$ Wen-Hou Wei ${ }^{1}$ \\ Received: 30 November 2017 / Revised: 16 January 2018/Published online: 21 February 2018 \\ (C) The Chinese Society for Metals and Springer-Verlag GmbH Germany, part of Springer Nature 2018
}

\begin{abstract}
Three-dimensional parts of the $30 \mathrm{CrMnSiA}$ steel were successfully fabricated using selective laser melting (SLM). The microstructures and mechanical properties of the SLM-processed 30CrMnSiA samples were investigated by scanning electron microscope and transmission electron microscopy. The results indicate that the microstructures of the $30 \mathrm{CrMnSiA}$ samples consist mainly of lath martensite and acicular martensite. The value of the surface roughness decreases with increasing laser energy density (LED) before it reaches a minimum and then increases with further increasing LED. The relative density, microhardness and ultimate tensile strength of the SLM-processed samples initially increase and then decrease with increasing LED. By taking the relative density, surface roughness, microhardness and ultimate tensile strength into account, the optimized LED should be in the range of $46.15-51.28 \mathrm{~J} \mathrm{~mm}^{-3}$ for the SLM-processed $30 \mathrm{CrMnSiA}$ alloys. In addition, the differences in the microstructures and mechanical properties between the conventionally wrought $30 \mathrm{CrMnSiA}$ sample and SLM-processed 30CrMnSiA samples were also studied.
\end{abstract}

Keywords $30 \mathrm{CrMnSiA} \cdot$ Selective laser melting $\cdot$ Laser energy density $\cdot$ Microstructure $\cdot$ Mechanical properties

\section{Introduction}

Selective laser melting (SLM) is one of the most promising additive manufacturing technologies. It is gaining popularity in the fabrication of high quality, geometrically highcomplexed and near-net shaped metallic parts directly from three-dimensional (3D) CAD (computer-aided design) models [1-5]. Nowadays, the SLM technique is increasingly used in the aerospace [6, 7], automobile [8], biomedicine [9-12] and industrial mold [13, 14] because it has significant advantages such as short design and production cycle, ability to handle complex shapes and low material wastage $[15,16]$. However, compared to the conventional

Available online at http://link.springer.com/journal/40195

Lin-Zhi Wang and Wen-Hou Wei have contributed equally to this work.

Wen-Hou Wei

weiwenhou@cigit.ac.cn

1 Chongqing Key Laboratory of Additive Manufacturing Technology and Systems, Chongqing Institute of Green and Intelligent Technology, Chinese Academy of Sciences, Chongqing 400714, China manufacturing processes like machining, the SLM technique still presents some significant weaknesses such as poor surface quality $[17,18]$; In addition, the non-optimal SLM processing parameters may cause inner defects such as presences of incompletely molten powder particles, clustered pores, entrapped gas bubbles and cracks [19-21].

Generally, the surface quality and mechanical properties of the SLM-processed parts vary significantly, depending on the processing parameters such as laser power, scanning speed, scan line spacing and scanning strategy; these processing parameters directly affect the melting and solidification behavior of the metallic powder. Consequently, a considerable research effort has focused on the effects of the SLM processing parameters on the microstructures and mechanical properties of various metallic parts. Kruth et al. [22] reported the importance of SLM processing parameters such as laser power and scanning strategies for obtaining full-density iron-based metal parts. Song et al. [23] fabricated a nearly fully dense Ti-6Al-4V part with excellent mechanical properties at a laser power of $110 \mathrm{~W}$ and a scanning speed of $0.4 \mathrm{~m} \mathrm{~s}^{-1}$. They also presented the correlation between processing parameters and porosity formation. Sun et al. [24] provided an optimized processing window which improved SLM build speed without loss of 
the mechanical properties of the $316 \mathrm{~L}$ stainless steel. Gong et al. [25] discussed the role of laser energy input in the SLM process and classified different processing zones corresponding to an incomplete melting, fully dense material and over-melting. So far, numerous studies on SLM of the stainless steels [24] and the alloys of Ti-based [26, 27], Mg-based [28], Al-based [29] and Ni-based [30] have been reported. Nevertheless, there is no available literature that deals with the structures and mechanical properties of the $30 \mathrm{CrMnSiA}$ steel parts fabricated by SLM technique.

In this study, we aim to investigate the influences of designed processing parameters on the structural and mechanical properties such as microstructure, surface roughness, relative density, microhardness, ultimate tensile strength and fracture behavior of the SLM-processed $30 \mathrm{CrMnSiA}$ parts. Such an understanding of the processing parameters is critical for improving the quality of the $30 \mathrm{CrMnSiA}$ parts fabricated using this technique.

\section{Experimental}

\subsection{Powder Used}

The spherical $30 \mathrm{CrMnSiA}$ powder were produced via radio-frequency plasma spheroidization (supplied by the Chongqing Institute of Green and Intelligent Technology, Chinese Academy of Sciences, China). The contents of the elements in $30 \mathrm{CrMnSiA}$ powder (in Table 1) were measured using an inductively coupled plasma atomic emission spectroscopy (ICP-AES, Thermo Scientific iCAP6300, USA). The morphology was observed using a field emission scanning electron microscope (FE-SEM, JEOL, JSM$7800 \mathrm{~F}$, Japan). The flow properties were collected using a powder flowability analyzer (Freeman FT4 powder rheometer, UK).

Figure 1a shows the morphology of the spherical 30CrMnSiA powder. The particles exhibit spherical shape with smooth surfaces. A favorable particle size distribution range between 5 and $50 \mu \mathrm{m}$ was confirmed by mechanical sieving of the powder. Figure $1 \mathrm{~b}$ shows the flow properties of the spherical $30 \mathrm{CrMnSiA}$ powder. The basic flowability energy (BFE) and specific energy (SE) are $3915 \mathrm{~mJ}$ and $3.18 \mathrm{~mJ} \mathrm{~g}^{-1}$, respectively. The value of the flow rate index (FRI $=1.07)$ indicates that the behavior of the powder is highly sensitive to the flow rate [31]. Generally, the powder with higher degrees of sphericity and reasonable particle size distributions have better flowability [32]. The results shown in Fig. 1 indicate that the spherical 30CrMnSiA powder have good flowability in this study.

\subsection{Selective Laser Melting Process}

The spherical powder were processed by a selective laser melting machine (AM250, Renishaw, UK) that employed a 1070-nm pulsed fiber laser, with a power as high as $200 \mathrm{~W}$. During the SLM process, the chamber was purged with argon until the oxygen content was $<500 \mathrm{ppm}$, and a slight positive pressure of approximately 15 mbar was applied inside of the chamber.

Laser energy density (LED) is an average process energy applied to a volumetric unit of material and defined by $[33,34]$,

$\mathrm{LED}=\frac{P}{v h d}$

where $P, v, h$ and $d$ are laser power, scanning speed, hatch spacing and layer thickness, respectively. A pulse laser applied in this study, $v$, can be determined by [35]

$v=\frac{P_{\mathrm{d}}}{T_{\mathrm{e}}}$

here $P_{\mathrm{d}}$ is point distance and $T_{\mathrm{e}}$ is exposure time. Thus, LED is given by

$\mathrm{LED}=\frac{P T_{\mathrm{e}}}{P_{\mathrm{d}} h d}$

In this study, $P_{\mathrm{d}}, h, d$ and laser spot diameter were 130 , 130,30 and $135 \mu \mathrm{m}$, respectively. The LEDs of the SLMprocessed samples are listed in Table 2.

\subsection{Characterization}

The microstructures of the $30 \mathrm{CrMnSiA}$ samples were investigated using an SEM and a transmission electron microscopy (TEM, Tecnai G2 F30, FEI, USA). The measurements of the surface roughness were carried out on a step profiler (Alpha-step IQ, KLA Tencor, USA). The density was measured using an electronic densimeter (BR120, Bairong, China). The location and size of the defects in the samples were detected by an industrial X-ray computed tomography (ICT, XTH 225, Nikon Metrology, Japan) which provided cross-sectional images and 3D images of the samples. Microhardness was measured on the polished surface under a 500-g load and a 20-s dwell time using a micro-Vickers hardness tester (Ahvd-1000XYZ,
Table 1 Chemical composition of the $30 \mathrm{CrMnSiA}$ powder in this work

\begin{tabular}{llllllllll}
\hline Element & $\mathrm{C}$ & $\mathrm{Si}$ & $\mathrm{Mn}$ & $\mathrm{Cr}$ & $\mathrm{Ni}$ & $\mathrm{Co}$ & $\mathrm{Mo}$ & $\mathrm{Cu}$ & $\mathrm{Fe}$ \\
\hline Composition (wt\%) & 0.25 & 1.05 & 0.9 & 3.74 & 1.99 & 0.058 & 0.48 & 0.02 & Balance \\
\hline
\end{tabular}



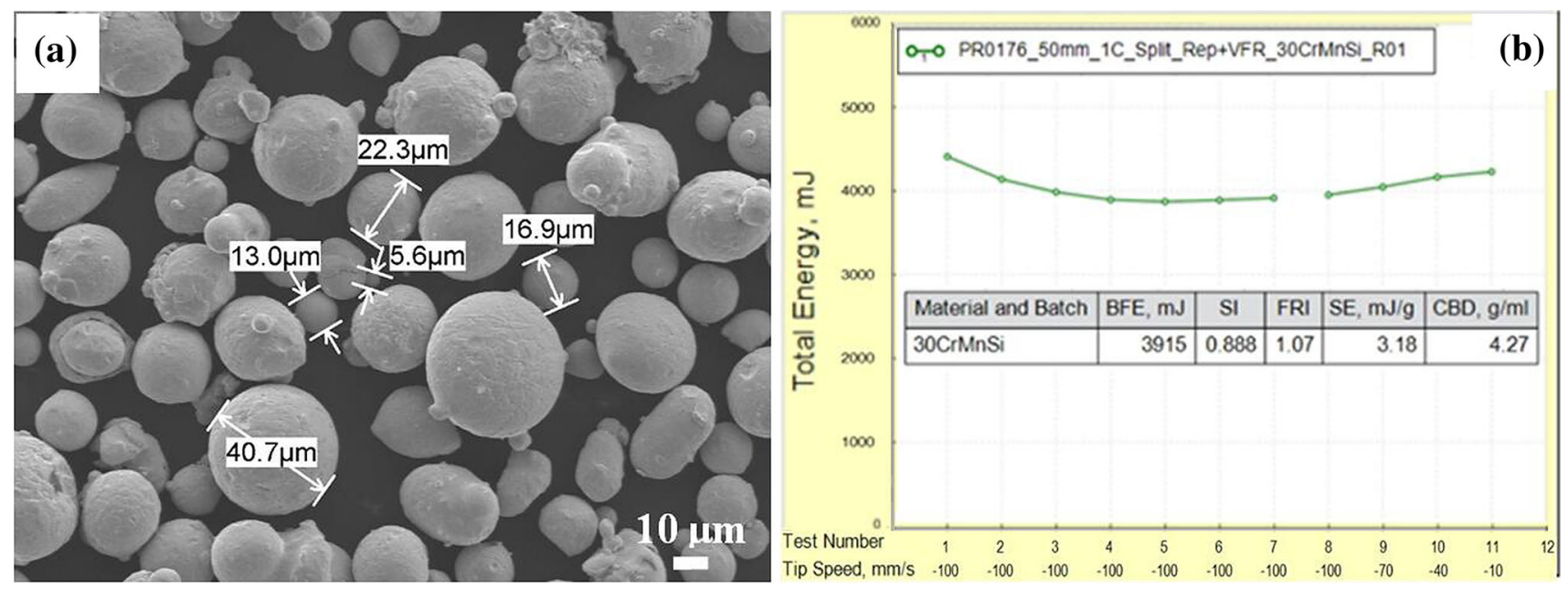

Fig. 1 a Morphologies, b flow properties of the spherical 30CrMnSiA powder

Table 2 Laser power, exposure time and LEDs used in the SLM-processed 30CrMnSiA samples

\begin{tabular}{lll}
\hline Laser power $(\mathrm{W})$ & Exposure time $(\mu \mathrm{s})$ & Laser energy density $\left(\mathrm{J} \mathrm{mm}^{-3}\right)$ \\
\hline 170 & 130 & 43.59 \\
180 & 130 & 46.15 \\
190 & 130 & 48.72 \\
200 & 130 & 51.28 \\
200 & 160 & 63.12 \\
\hline
\end{tabular}

China). A pyramidal diamond indenter was used to estimate the local microhardness information. The tensile tests were performed at room temperature using a universal testing machine (MTS TestStar 810, USA) with a strain rate of $0.5 \mathrm{~mm} \mathrm{~min}^{-1}$. The tensile fracture morphologies were also observed by the SEM.

\section{Results and Discussion}

\subsection{Microstructure}

Figure 2 shows the microstructures of the 30CrMnSiA samples. It can be observed that both the microstructures of the wrought sample and SLM-processed samples consist mainly of lath martensite and acicular martensite. As can be expected, the width of the martensite laths in the SLMprocessed samples is slightly smaller than that of the wrought sample. This can be attributed to the relatively faster cooling rate during the SLM process [36-38]. There is no obvious difference in the SLM-processed samples since they exhibit extremely similar microstructure characteristics.

Figure $3 \mathrm{a}, \mathrm{b}$ show the TEM morphologies of the wrought 30CrMnSiA sample and the SLM-processed 30CrMnSiA sample with a typical LED of $46.15 \mathrm{~J} \mathrm{~mm}^{-3}$, respectively. The insets present corresponding diffraction patterns in the white rectangles. The diffraction patterns of the samples exhibit typical crystal structural characteristics [39]. The bright-field TEM images show that the microstructures of both the wrought sample and SLMprocessed sample consist mainly of lath martensite and acicular martensite as white arrows indicated. They also exhibit the high density of dislocations in the lath/acicular martensite structures. The width of the martensite laths in the SLM-processed sample is approximately 200-300 nm, which is smaller than that of the wrought sample. This is in accordance with the microstructures of the 30CrMnSiA samples as shown in Fig. 2.

\subsection{Relative Density and Surface Roughness}

Industrial computed tomography (ICT) is an efficient and powerful nondestructive testing technology, which uses measurements of X-ray transmission in the investigated object to compute the relative $\mathrm{X}$-ray linear attenuation coefficient and presents them as a cross section image map [40]. ICT has been applied to charge quality inspection because it provides quantitative information about the constituents, dimensions, density and defects of the object. Figure $4 \mathrm{a}$, c presents an ICT cross section image map of the wrought 30CrMnSiA sample and the SLM-processed 30CrMnSiA sample with a typical LED of $46.15 \mathrm{~J} \mathrm{~mm}^{-3}$, respectively. Figure $4 \mathrm{~b}, \mathrm{~d}$ illustrates the location and 

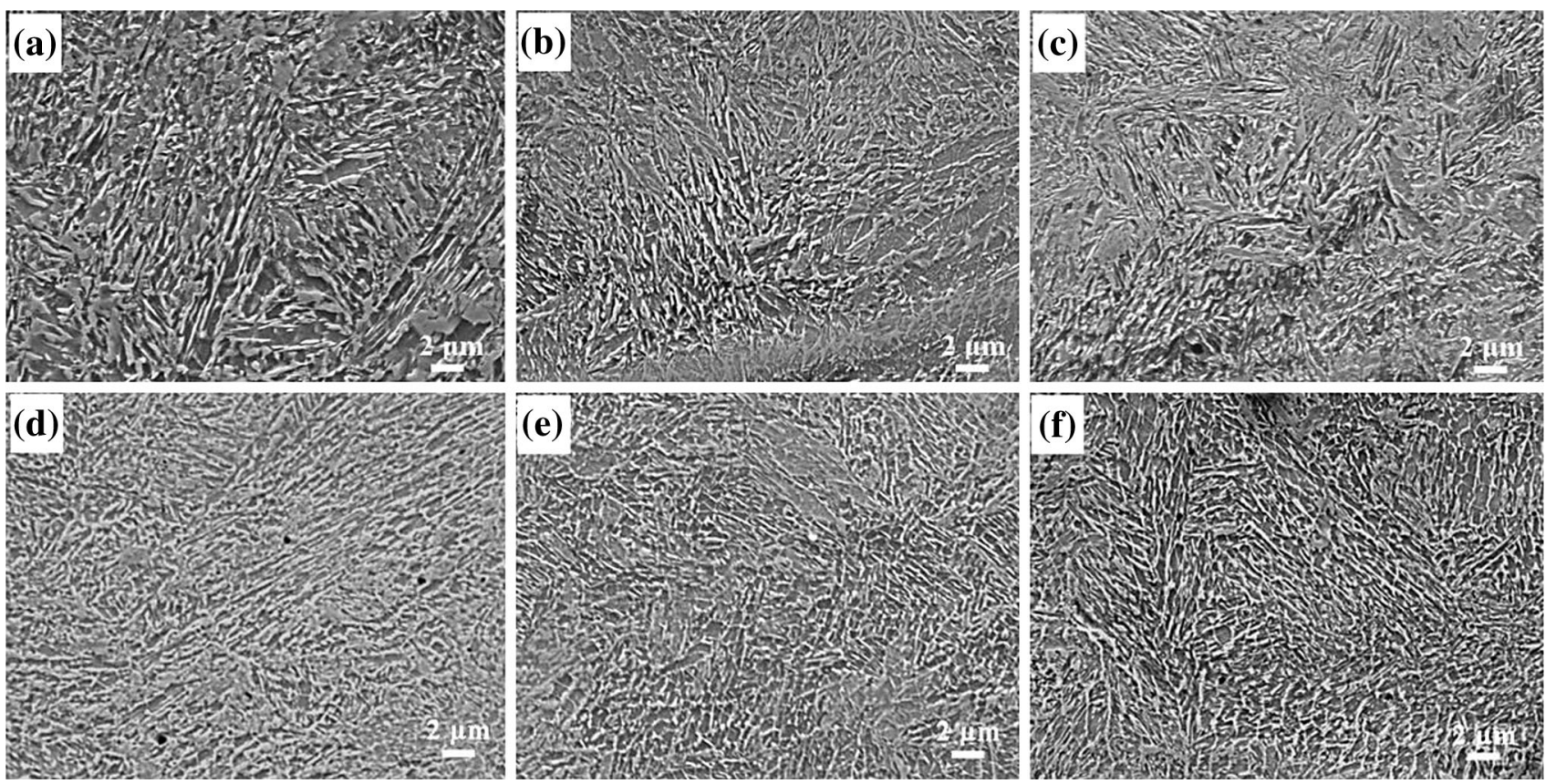

Fig. 2 Microstructures of a the wrought 30CrMnSiA sample and the SLM-processed samples with different LEDs of b 43.59, c 46.15, d 48.72, e $51.28, \mathbf{f} 63.12 \mathrm{~J} \mathrm{~mm}^{-3}$
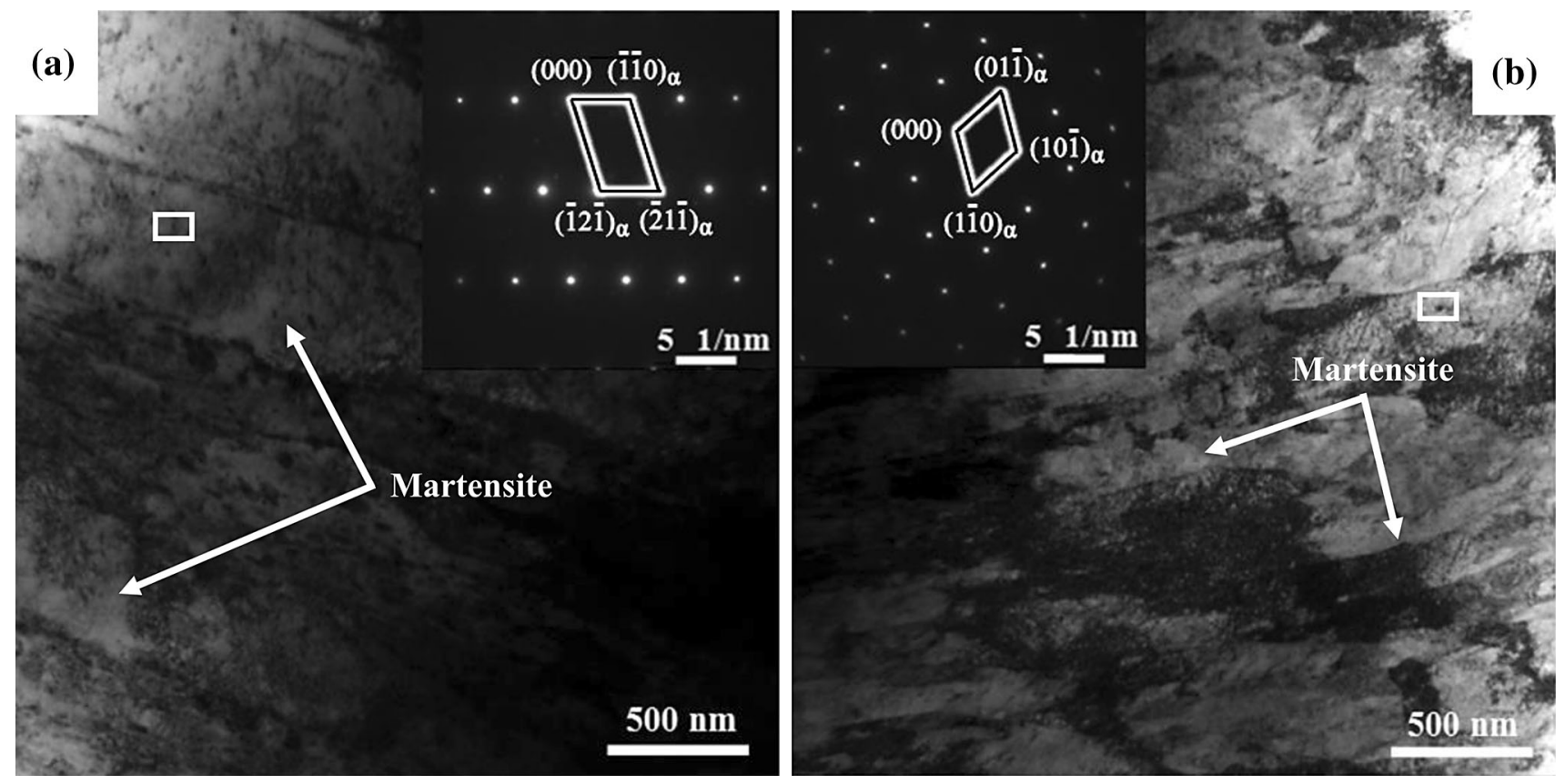

Fig. 3 TEM images of a the wrought $30 \mathrm{CrMnSiA}$ sample, $\mathbf{b}$ the SLM-processed sample with an LED of $46.15 \mathrm{~J}^{-3}$. The insets present corresponding diffraction patterns in the white rectangles

distribution of all defects observed throughout the volumes of the wrought sample and SLM-processed sample, respectively. As arrows indicated, most of the defects are irregular in shape and $<200 \mu \mathrm{m}$ in diameter. The number of defects in the SLM-processed sample is less than that of the wrought sample. These defects determine the structural properties such as the porosity and relative density of the samples and directly affect their macroscopic mechanical properties which include hardness, ultimate tensile strength and fracture behavior [41-44].

Figure 5 presents the relative density and surface roughness $\left(R_{\mathrm{a}}\right)$ of the SLM-processed 30CrMnSiA samples 

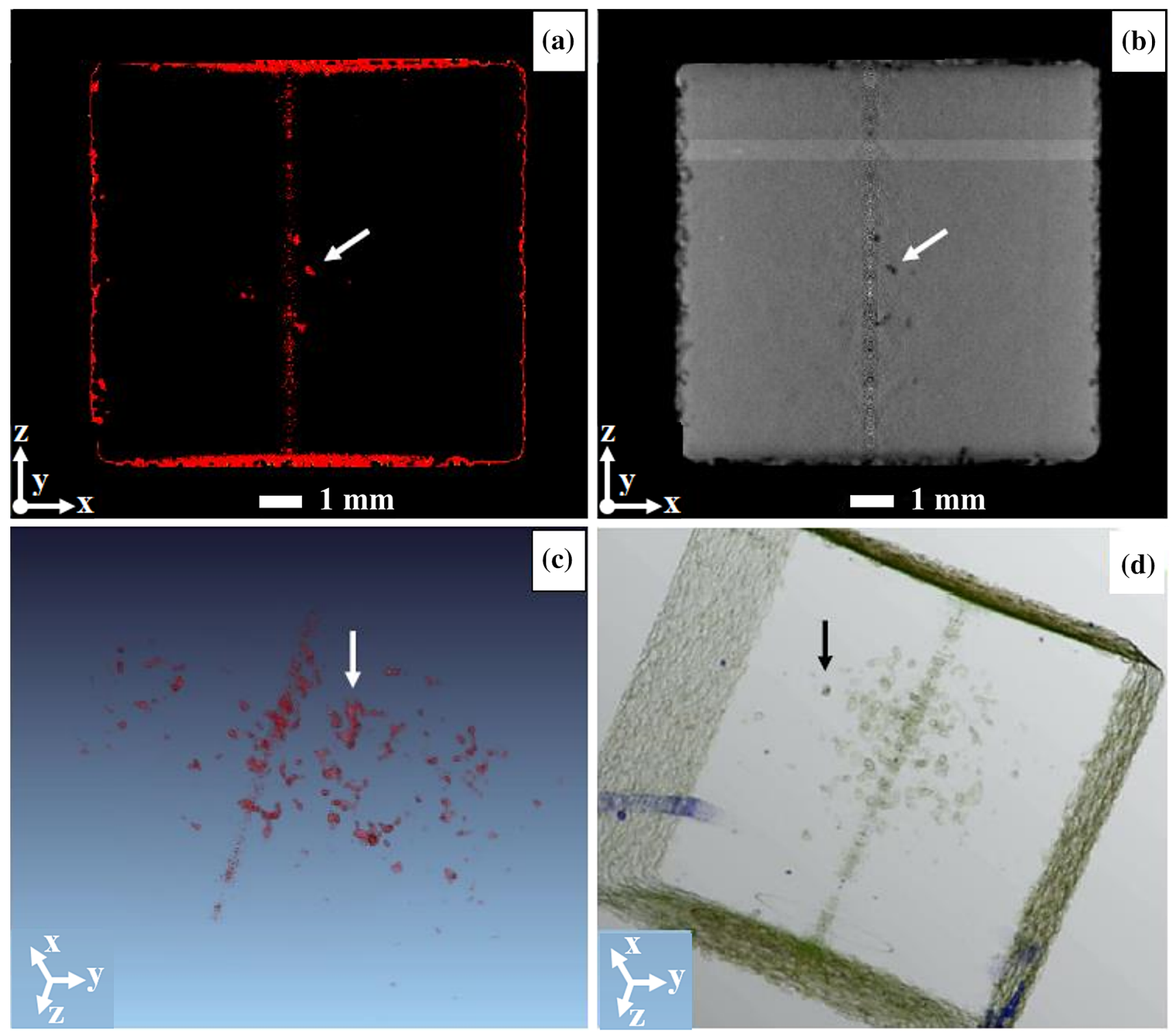

Fig. 4 ICT images of the $30 \mathrm{CrMnSiA}$ samples, a cross section image map of $\mathbf{a}$ the wrought sample, $\mathbf{b}$ the SLM-processed sample with an LED of $46.15 \mathrm{~J} \mathrm{~mm}^{-3}$, the 3D image of $\mathbf{c}$ the wrought sample, $\mathbf{d}$ the SLM-processed sample

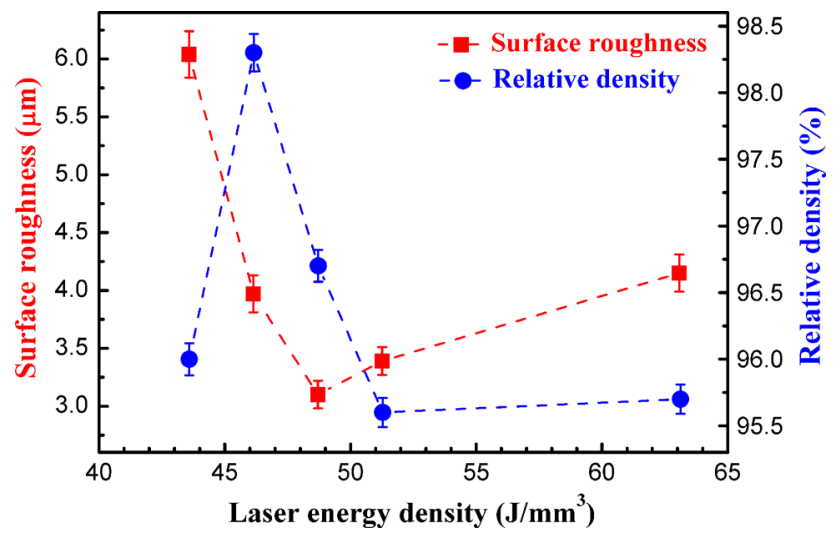

Fig. 5 Surface roughness and relative density as functions of LED of the SLM-processed 30CrMnSiA samples as functions of the LED. With the increase in LED, the relative density increases initially and then decreases. The maximum relative density of $98.3 \%$ occurs at an LED of $46.15 \mathrm{~J} \mathrm{~mm}^{-3}$, indicating the sample is well densified. The value of the surface roughness decreases with increasing LED before it reaches a minimum and then increases with further increasing LED. The minimum value of the surface roughness, $R_{\mathrm{a}}=3.10 \mu \mathrm{m}$, is achieved at an LED of $48.72 \mathrm{~J} \mathrm{~mm}^{-3}$.

The relative density of the $30 \mathrm{CrMnSiA}$ alloy is lower, and the surface roughness is greater at low LED values. This is because the incomplete melting and lack of fusion of the powder which cause higher viscidity and poor wettability in the melt pool [45], even cause obvious balling 
effect [46]. The liquid phase is difficult to spread between two near laser scanning tracks, and the width and depth of the melt pool are smaller than the hatch spacing and layer thickness, respectively. Consequently, some pores inevitably appear between the layers, thereby leading to lower relative density and greater surface roughness.

The laser energy becomes powerful enough to melt the powder with the increase in LED, and the increasing laser energy input improves the activities between the laser beam and powder. Accordingly, the viscidity of the liquid phase in the melt pool decreases, and the flowability increases. Hence, a good melt spreading and penetration result in excellent metallurgical bonding between the adjacent layers.

With a further increase in LED, the increased size of the melt pool results in increased overlap, which deteriorates the relative density and surface roughness. On the one hand, at a higher LED, excess energy input may evaporate the low melting point elements in the molten materials as reported by Vilaro et al. [47]. Due to fast solidification during the SLM process, the evaporated gases trapped within the melt pool, leading to the formation of miniature pores [48], thereby decreasing the relative density of the sample. On the other hand, at a higher LED, a large temperature gradient between the melt pool and the solidified laser scanning tracks results in stronger Marangoni convection [49]. Thus, over-melting and over-heating of liquid phase lead to increased instability and thus deteriorate the surface roughness of the sample.

\subsection{Microhardness, Ultimate Tensile Strength and Fracture Mechanism}

Figure 6 shows the microhardness and ultimate tensile strength of the SLM-processed 30CrMnSiA samples at different LEDs. The microhardness and ultimate tensile strength of the wrought $30 \mathrm{CrMnSiA}$ sample are $276 \mathrm{HV}$

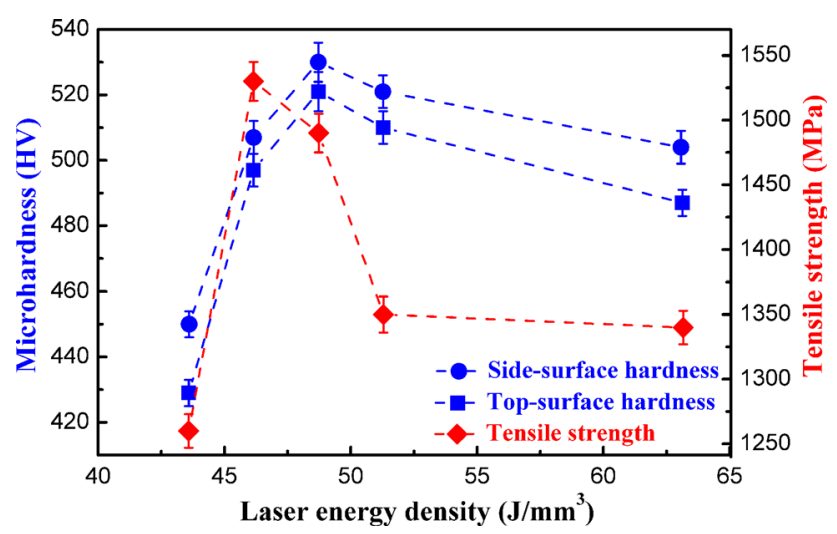

Fig. 6 Microhardness and ultimate tensile strength of the SLMprocessed $30 \mathrm{CrMnSiA}$ samples at different LEDs and $830 \mathrm{MPa}$, respectively. The hardness and ultimate tensile strength of the SLM-processed samples are significantly better compared with those of the wrought sample, and this can be attributed to the rapid melting and cooling of each layer in the SLM process, which always lead to a fine microstructure with fine grain [50]. As can be expected, the fine martensitic structure enhances the microhardness and ultimate tensile strength of the SLMprocessed samples. In addition, compared to the wrought sample, less number of defects in the SLM-processed samples (shown in Fig. 3) can also lead to higher microhardness and ultimate tensile strength.

As noted, the microhardness and ultimate tensile strength of the SLM-processed samples initially increase with the increase in LED. The microhardnesses of the top surface and side surface reach the maximum values of 521 and $530 \mathrm{HV}$, respectively, at an LED of $48.72 \mathrm{~J} \mathrm{~mm}^{-3}$. The ultimate tensile strength reaches a maximum value of $1530 \mathrm{MPa}$ at an LED of $46.15 \mathrm{~J} \mathrm{~mm}^{-3}$. And then the microhardness and ultimate tensile strength decrease with further increase in the LED value.

When the LED is low, the powder are only partially melted because of deficient laser energy input. The poor metallurgical bonding between the adjacent layers results in poor mechanical properties including the microhardness and ultimate tensile strength of the sample; When the LED is too high, over-melting and over-heating of liquid phase lead to the evaporated gas trapped within the melt pool, leading to the formation of pores during fast solidification of the SLM process. In addition, the stronger Marangoni convection and instability of the melt pool derived from overlarge temperature gradient are unfavorable to the solidification of SLM-produced sample. Thus, the mechanical properties of the samples become less desirable.

Generally, the mechanical properties have a close relationship with the densification level that corresponds to the resistance to plastic deformation or rupture [23]. This is attributed to the clustered pores within the material collapsing under certain load, whereas well-densified material without obvious defects has stronger resistance to deformation or rupture. Since almost the same microstructure characteristics have been observed for all the SLM-processed samples, the extremely similar dimension of the lath/acicular martensite only slightly affects the mechanical properties such as microhardness and ultimate tensile strength. Accordingly, the mechanical properties of the SLM-processed samples mainly depend on their densification levels in this study. In summary, by taking the relative density, surface roughness, microhardness and ultimate tensile strength into account, the optimized LED should be in the range of $46.15-51.28 \mathrm{~J} \mathrm{~mm}^{-3}$ for the SLM-processed 30CrMnSiA samples. 

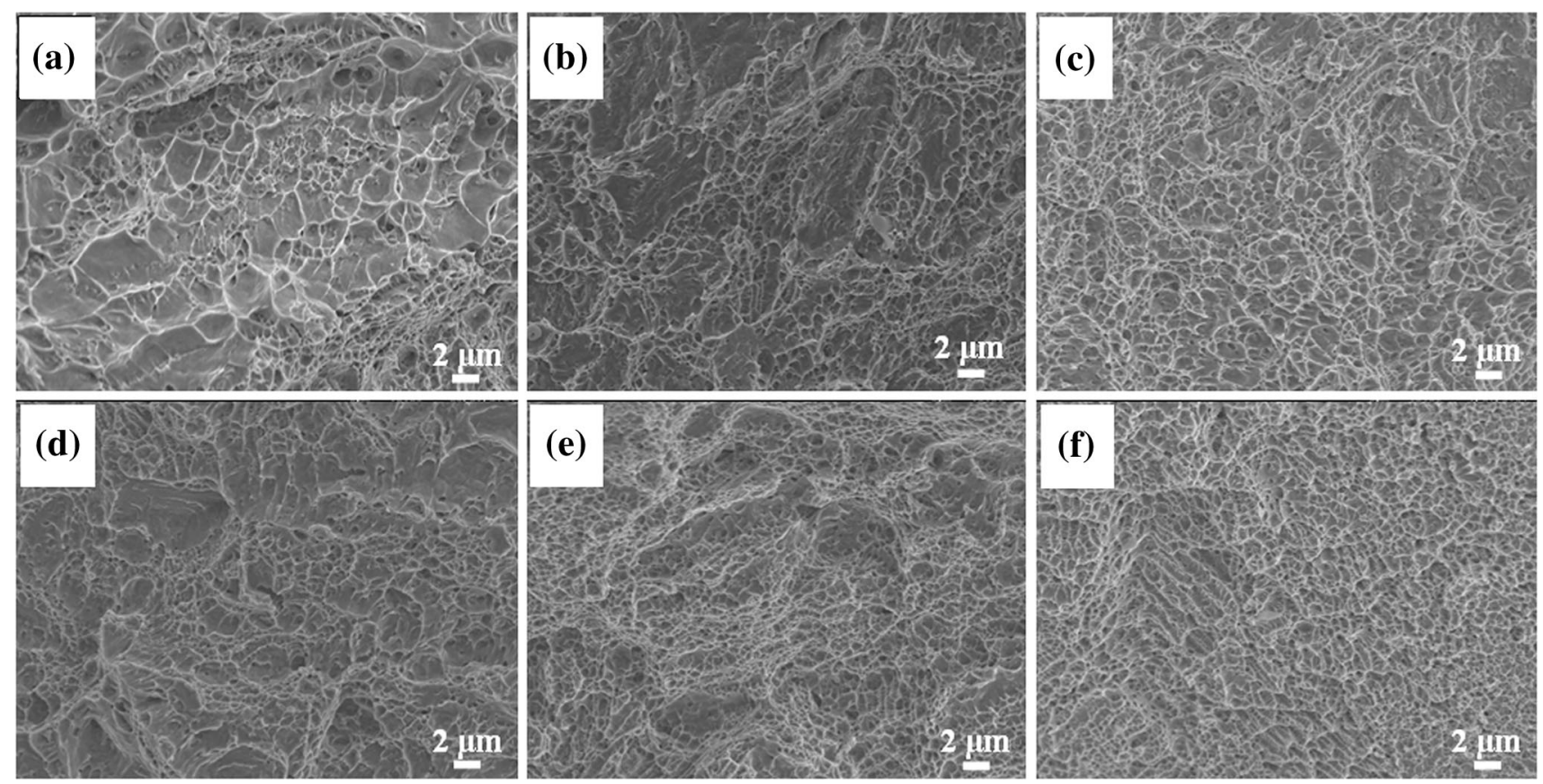

Fig. 7 Tensile fracture morphologies of a the wrought 30CrMnSiA sample and the SLM-processed samples with different LEDs of b 43.59, c 46.15 , d 48.72 , e 51.28 , f $63.12 \mathrm{~J} \mathrm{~mm}^{-3}$

Figure 7 illustrates the tensile fracture morphologies of the $30 \mathrm{CrMnSiA}$ samples. Fractography of the wrought $30 \mathrm{CrMnSiA}$ sample exhibits a typical dimple characteristic of ductile fracture. The deep and large dimples on the tensile fracture surface indicate high plastic toughness [51]. However, the SLM-processed 30CrMnSiA samples show a mixed mode of ductile and brittle fracture, which predominantly show small and shallow dimples along with some quasi-cleavage fracture features observed in some local zones. The fine martensitic structure can improve the strength of the sample, but at the expense of ductility. Thus, the fracture feature of the SLM-processed samples can be interpreted as the high brittleness and low ductility of martensitic microstructure as a consequence of faster cooling rate during the SLM process.

\section{Conclusions}

The $30 \mathrm{CrMnSiA}$ parts were successfully fabricated by selective laser melting. Their microstructures and mechanical properties were studied and compared to those of the wrought $30 \mathrm{CrMnSiA}$ sample. Conclusions could be drawn as follows:

1. The microstructures of the $30 \mathrm{CrMnSiA}$ samples consist mainly of lath martensite and acicular martensite. A high density of dislocations appears in the lath/ acicular martensite structures.
2. With increasing LED, the relative densities of the SLM-processed 30CrMnSiA samples increase initially and then decrease. The maximum relative density of $98.3 \%$ occurs at an LED of $46.15 \mathrm{~J} \mathrm{~mm}^{-3}$. The value of the surface roughness decreases with increasing LED before it reaches a minimum and then increases with further increasing LED. The minimum value of surface roughness, $R_{\mathrm{a}}=3.10 \mu \mathrm{m}$, is achieved at an LED of $48.72 \mathrm{~J} \mathrm{~mm}^{-3}$.

3. The microhardness and ultimate tensile strength of the SLM-processed 30CrMnSiA samples first increase and then decrease with the increase in LED. The maximum value of the microhardness of the top surface and side surface is 521 and $530 \mathrm{HV}$, respectively, at an LED of $48.72 \mathrm{~J} \mathrm{~mm}^{-3}$. The maximum value of the ultimate tensile strength is $1530 \mathrm{MPa}$ at an LED of $46.15 \mathrm{~J} \mathrm{~mm}^{-3}$.

4. The tensile fracture morphologies of the SLM-processed $30 \mathrm{CrMnSiA}$ samples exhibit a mixed mode of complex ductile and brittle fracture, which predominantly show small and shallow dimples with some quasi-cleavage fracture features observed in some local zones.

Acknowledgements This research was financially supported by the National Natural Science Foundation of China (Grant No. 51405467), the Strategic Industry Key Generic Technology Innovation Project of Chongqing (No. cstc2015zdcy-ztzx50005) and the Entrepreneurship and Innovation Support Program for Chongqing Overseas Returned Scholars (No. cx2017040). W. H. Wei acknowledges the financial 
support from the West Light Foundation of the Chinese Academy of Sciences.

\section{References}

[1] G. Kasperovich, J. Haubrich, J. Gussone, G. Requena, Mater. Des. 105, 160 (2016)

[2] J. Suryawanshi, K.G. Prashanth, U. Ramamurty, Mater. Sci. Eng. A 696, 113 (2017)

[3] P.Y. Lin, Z.H. Zhang, S.H. Kong, H. Zhou, Y.H. Liang, X. Tong, L.Q. Ren, Acta Metall. Sin. (Engl. Lett.) 29, 985 (2016)

[4] L. Jinhui, L. Ruidi, Z. Wenxian, F. Liding, Y. Huashan, Mater. Sci. Technol. 26, 1259 (2010)

[5] M. Garibaldi, I. Ashcroft, M. Simonelli, R. Hague, Acta Mater. 110, 207 (2016)

[6] M.F. Cruz, A.V. Borille, J. Braz. Soc. Mech. Sci. 39, 177 (2017)

[7] M. Seabra, J. Azevedo, A. Araujo, L. Reis, E. Pinto, N. Alves, R. Santos, J.P. Mortagua, in Selective Laser Melting (SLM) and Topology Optimization for Lighter Aerospace Components, XV Portuguese Conference on Fracture, PCF 2016, vol. 1 (2016), p. 289

[8] T.V. Tarasova, A.P. Nazarov, M.V. Prokof'ev, Phys. Met. Metall. 116, 601 (2015)

[9] L.C. Zhang, H. Attar, Adv. Eng. Mater. 18, 463 (2016)

[10] N.A.W. Dai, L.C. Zhang, J.X. Zhang, X. Zhang, Q.Z. Ni, Y. Chen, M.L. Wu, C. Yang, Corros. Sci. 111, 703 (2016)

[11] Y.J. Liu, Z. Liu, Y. Jiang, G.W. Wang, Y. Yang, L.C. Zhang, J. Alloys Compd. 735, 1414 (2018)

[12] L.C. Zhang, D. Klemm, J. Eckert, Y.L. Hao, T.B. Sercombe, Scr. Mater. 65, 21 (2011)

[13] J.H. Martin, B.D. Yahata, J.M. Hundley, J.A. Mayer, T.A. Schaedler, T.M. Pollock, Nature 549, 365 (2017)

[14] K.A. Ghany, S.F. Moustafa, Rapid Prototyp. J. 12, 86 (2006)

[15] C.Y. Yap, C.K. Chua, Z.L. Dong, Z.H. Liu, D.Q. Zhang, L.E. Loh, S.L. Sing, Appl. Phys. Rev. 2, 1 (2015)

[16] L.M. Yan, Y.W. Yuan, L.J. Ouyang, H. Li, A. Mirzasadeghi, L. Li, J. Alloys Compd. 688, 156 (2016)

[17] M. Krol, T. Tanski, Arch. Metall. Mater. 61, 945 (2016)

[18] G. Strano, L. Hao, R.M. Everson, K.E. Evans, J. Mater. Process. Technol. 213, 589 (2013)

[19] J. Han, J.J. Yang, H.C. Yu, J. Yin, M. Gao, Z.M. Wang, X.Y. Zeng, Rapid Prototyp. J. 23, 217 (2017)

[20] J.P. Choi, G.H. Shin, M. Brochu, Y.J. Kim, S.S. Yang, K.T. Kim, D.Y. Yang, C.W. Lee, J.H. Yu, Mater. Trans. 57, 1952 (2016)

[21] L.N. Carter, X. Wang, N. Read, R. Khan, M. Aristizabal, K. Essa, M.M. Attallah, Mater. Sci. Technol. 32, 657 (2016)

[22] J.P. Kruth, L. Froyen, J. Van Vaerenbergh, P. Mercelis, M. Rombouts, B. Lauwers, J. Mater. Process. Technol. 149, 616 (2004)

[23] B. Song, S.J. Dong, B.C. Zhang, H.L. Liao, C. Coddet, Mater. Des. 35, 120 (2012)

[24] Z.J. Sun, X.P. Tan, S.B. Tor, W.Y. Yeong, Mater. Des. 104, 197 (2016)

[25] H. Gong, K. Rafi, T. Starr, B. Stucker, The effects of processing parameters on defect regularity in $\mathrm{Ti}-6 \mathrm{Al}-4 \mathrm{~V}$ parts fabricated by selective laser melting and electron beam melting, Paper presented at the 24th annual international solid freeform fabrication symposium - an additive manufacturing conference, Austin, 424-429 August 2013
[26] J. Tong, C.R. Bowen, J. Persson, A. Plummer, Mater. Sci. Technol. 33, 138 (2017)

[27] E. Chlebus, B. Kuznicka, R. Dziedzic, T. Kurzynowski, Mater. Sci. Eng. A 620, 155 (2015)

[28] K. Kempen, L. Thijs, J. Van Humbeeck, J.P. Kruth, Mater. Sci. Technol. 31, 917 (2015)

[29] H. Zhang, H.H. Zhu, T. Qi, Z.H. Hu, X.Y. Zeng, Mater. Sci. Eng. A 656, 47 (2016)

[30] K.N. Amato, S.M. Gaytan, L.E. Murr, E. Martinez, P.W. Shindo, J. Hernandez, S. Collins, F. Medina, Acta Mater. 60, 2229 (2012)

[31] W.H. Wei, L.Z. Wang, T. Chen, X.M. Duan, W. Li, Adv. Powder Technol. 28, 2431 (2017)

[32] J.F. Gamble, W.S. Chiu, M. Tobyn, Pharm. Dev. Technol. 16, $542(2011)$

[33] L. Thijs, F. Verhaeghe, T. Craeghs, J. Van Humbeeck, J.P. Kruth, Acta Mater. 58, 3303 (2010)

[34] M. Mazur, M. Leary, S.J. Sun, M. Vcelka, D. Shidid, M. Brandt, Int. J. Adv. Manuf. Technol. 84, 1391 (2016)

[35] L.C. Zhang, T.B. Sercombe, Key Eng. Mater. 520, 226 (2012)

[36] F. Bartolomeu, S. Faria, O. Carvalho, E. Pinto, N. Alves, F.S. Silva, G. Miranda, Mater. Sci. Eng. A 663, 181 (2016)

[37] E.A. Jagle, P.P. Choi, J. Van Humbeeck, D. Raabe, J. Mater. Res. 29, 2072 (2014)

[38] H. Attar, M. Calin, L.C. Zhang, S. Scudino, J. Eckert, Mater. Sci. Eng. A 593, 170 (2014)

[39] L. Dupont, M. Hervieu, D. Pelloquin, G. Nowogrocki, M. Touboul, J. Solid State Chem. 135, 282 (1998)

[40] I. Maskery, N.T. Aboulkhair, M.R. Corfield, C. Tuck, A.T. Clare, R.K. Leach, R.D. Wildman, I.A. Ashcroft, R.J.M. Hague, Mater. Charact. 111, 193 (2016)

[41] Y.F. Shen, D.D. Gu, P. Wu, Mater. Sci. Technol. 24, 1501 (2008)

[42] Y.J. Liu, S.J. Li, H.L. Wang, W.T. Hou, Y.L. Hao, R. Yang, T.B. Sercombe, L.C. Zhang, Acta Mater. 113, 56 (2016)

[43] Y.J. Liu, H.L. Wang, S.J. Li, S.G. Wang, W.J. Wang, W.T. Hou, Y.L. Hao, R. Yang, L.C. Zhang, Acta Mater. 126, 58 (2017)

[44] M. Grasso, B.M. Colosimo, Meas. Sci. Technol. 28, 04405 (2017)

[45] V. Gunenthiram, P. Peyre, M. Schneider, M. Dal, F. Coste, R. Fabbro, J. Laser Appl. 29, 022303 (2017)

[46] H. Salem, H.G. Salem, M.M. Attallah, Composite powder consolidation using selective laser melting: input energy/porosity morphology/balling effect relation. Paper presented at the TMS 2017 146th annual meeting and exhibition supplemental proceedings, San Diego convention center, San Diego, 169-180 February 2017

[47] T. Vilaro, C. Colin, J.D. Bartout, Metall. Mater. Trans. A 42, $3190(2011)$

[48] S. Tammas-Williams, H. Zhao, F. Leonard, F. Derguti, I. Todd, P.B. Prangnell, Mater. Charact. 102, 47 (2015)

[49] G.M. Moatimid, M.A. Hassan, Math. Probl. Eng. 2013, 27 (2013)

[50] L.E. Murr, E.V. Esquivel, S.A. Quinones, S.M. Gaytan, M.I. Lopez, E.Y. Martinez, F. Medina, D.H. Hernandez, E. Martinez, J.L. Martinez, S.W. Stafford, D.K. Brown, T. Hoppe, W. Meyers, U. Lindhe, R.B. Wicker, Mater. Charact. 60, 96 (2009)

[51] N.D. Alexopoulos, M. Tiryakioglu, Metall. Mater. Trans. A 40, 702 (2009) 